\title{
PENGARUH PEMBELAJARAN AUDIO VISUAL TERHADAP KEMAMPUAN RENANG GAYA DADA
}

\author{
Karno Dinata $^{1}$, Hariadi ${ }^{2}$, Didik Daniyantara ${ }^{3}$, Nopi Hariadi ${ }^{4}$, Jumesam ${ }^{5}$, Putra Jaya ${ }^{6}$ \\ Email: $\underline{\text { karnodinata111@gmail.com }}{ }^{1}, \underline{\text { hariadi12113@gmail.com }}{ }^{2}, \frac{\text { daniyantara didik@yahoo.com }}{\mathbf{3}}$, \\ 060614.harijadi@gmail.com ${ }^{4}$, mr.jumesam.lombok@gmail.com ${ }^{\mathbf{5}}$, jaya75959@ gmail.com ${ }^{\mathbf{6}}$
}

1,2,3,4,5 Prodi Penjaskesrek, Fakultas Ilmu Pendidikan (FIP), Universitas Hamzanwadi

\begin{abstract}
Abstrak
Penelitian dilakukan karena hasil belajar siswa masih dibawah standar KKM, selain itu metode pembelajaran masih konvensional dan jarang menggunkan alat bantu berupa audio visual saat proses pemberlajaran dalam kelas. Dari hasil penelitian maka tujuan yang diperoleh ialah "ada pengaruh pembelajaran audio visual (video) terhadap kemampuan renang gaya dada Di SMP Islam Alhasanah Rekat Lauk" yang tergabung dalam ekstrakulikuler renang. Jenis penelitian menggunakan penelitian kuantitatif, metode pendekatan eksperimen. Populasi berjumlah 83 siswa SMP Islam Alhasanah Rekat Lauk. Sedangkan Sampel penelitian seluruh siswa yang tergabung dalam ekstrakulikuler renang berjumlah 20 siswa dari kelas 7 dan 8 . Instrument penelitian mengunakan lembar observasi. Teknik pengumpulan data dengan praktek renang gaya dada yang mengacu pada isi lebar observasi yaitu teknik renang gaya dada. Analisis data menggunakan rumus $\mathrm{t}$ test. Berdasarkan hasil penelitian dan pengumpulan data yang diperoleh pree test adalah 51,2, dan data yang diperoleh dari hasil post-test adalah 75,3 terjadi peningkatan yang signifikan sebesar 24,1. setelah diberikannya perlakuan. Selanjutnya Data diuji menggunakan uji-t dan diperoleh $t_{\text {hitung }}$ sebesar 13,586 dibandingkan dengan $t_{\text {tabel }}$ pada taraf signifikansi $5 \%$ dan n-1 (20-1=19) adalah 1,729. Karena $t_{\text {hitung }}$ lebih besar dari $t_{\text {tabel }}\left(t_{\text {hitung }}>t_{\text {tabel }}\right)$ atau ( 13,586>1,729), maka hipotesis $H_{0}$ ditolak sedangkan $H_{a}$ diterima, sehingga dapat ditarik kesimpulan ada pengaruh yang signifikan pembelajaran audio visual terhadap kemampuan renang gaya dada pada siswa SMP Islam Al-Hasanah Rekat Lauk.
\end{abstract}

Kata Kunci: Audio Visual, Renang Gaya Dada

\section{Abstract}

This study aims to determine the effect of audio-visual (video) learning on breaststroke swimming ability in Islamic Junior High School students Alhasanah Rekat Lauk who are members of the swimming extracurricular activity. This type of research is a quantitative study with an experimental method. The sample in this study were all students who joined the swimming extracurricular, totaling 20 people. Based on the results of the research and data collection obtained by the pretest was 51.2 before being given treatment, and the data obtained from the posttest results was 75.3 after the treatment was given. After that the data were distributed in the t-test and the results were 13,586 compared to the t-table at the 5\% significance level and $n-1(20-1=19)$ was 1,729.Because $t$-count is greater than $t$ table (t-count> t-table) or $(13,586>1,729)$, this means that the hypothesis Ho is rejected while Ha is accepted, so it can be concluded that there is an effect of audio-visual (video) learning. on the breaststroke swimming ability of Alhasanah Rekat Lauk Islamic Junior High School students.

Keyword: Audio Visual, Breaststroke Swimming 


\section{A. Pendahuluan}

Olahraga mempunyai peranan penting dalam kehidupan manusia. Dalam kehidupan yang modern ini manusia tidak bias dipisahkan dari kegiatan olahraga baik untuk meningkatkan prestasi maupun kebutuhan dalam menjaga kondisi tubuh agar tetap sehat. Dengan olahraga dapat membentuk manusia yang sehat jasmani dan rohani serta mempunyai watak disiplin dan pada akhirnya akan terbentuk manusia yang berkualitas. Adapun salah satu kegiatan olahraga yang disenangi dan digemari oleh masyarakat pada saat sekarang ini adalah renang. Kecelakaan di air sekarang banyak terjadi, baik di sungai, danau, atau pun dilaut lepas.Kecelakaan yang diakibatkan oleh tenggelamnya kapal-kapal besar dan perahuperahu kecil yang sedang berlayar, serta anak-anak maupun orang dewasa yang bermain diperairan. Ketika terjadi kecelakaan tersebut maka pertama kali yang di pikirkan adalah menyelamatkan diri, jika tidak bias menyelamatkan diri maka akan tenggelam ata uhal yang paling menakutkan adalah kematian. Kemampuan siswa yang terampil dalam berenang biasa menambah kepercayaan diri dalam bergaul. Selain itu renang juga dapat dijadikan sebagai alternative untuk perawatan atau terapi bagi yang cidera, terutama yang berkaitan dengan cidera persendian atau otot. Menurut Edo danYunus (2017:82), Mengatakan bahwa renang merupakan olahraga yang dilakukan di kolam renang yang mampu mempercepat pertumbuhan seseorang, memperkuat kardiresperasi serta mampu mengembalikan cidra ringan serta memberikan manfaat baik secara fisik maupun emosional. Manfaat dari renang tersebut antara lain untuk keselamatan diri, meningkatkan kebugaran jasmani, rehabilitasi, dan prestasi. Berdasarkan observasi peneliti diperoleh adanya beberapa permasalahan yang ditemukan didalam pembelajaran olahraga yaitu hasil belajar siswa yang dibawah setandar KKM (7.5) terutama dalam materi renang, Permasalahan yang lain ditemukan bahwa pembelajaran di SMP Islam Al-Hasanah Rekat Lauk jaran gsekali di berikan materi menggunakan audio visual, sehingga siswa juga merasa jenuh ketika menerima materi dari guru saja, tanpa menggunkan audio visual artinya siswa mampu melihar secara jelas disaat guru memeparkan materinya. Melihat permasalahan tersebut lalu peneliti melakukan penelitian selama satu bulan dan kemudian Terdapat peningkatan hasil belajar renang gaya dada baik pada aspek pengetahuan maupun kemapuan renang gaya dada. Sebagaimana penelitian ini diperkuat lagi oleh Rizal Bastomi (2018:8) dalam penelitiannya bahwa media audio visual tersebut berpengaruh signifikan pada siswa kelas VIII SMP 3 Sidoardjo.

\section{B. Metode}

Untuk memperoleh data yang sesuai dengan tujuan penelitian ini maka jenis penelitianini adalah kuantitatif dengan metode yang di gunakan adalah metode eksperimen. Penelitian eksperimen merupakan suatu cara untuk mencari hubungan sebab akibat (hubungan kausal) antara dua factor yang sengaja ditimbulkan oleh peneliti dengan mengeliminisasi atau mengurangi atau menyisihkan factor-faktor lain yang menggangu. (Arikunto, 2010:4). Dalam penelitian ini teknik yang digunakan dalam pengambilan sampel yaitu teknik Nonprobability Sampling yang meliputi Sampling Jenuh. Sampling jenuh adalah teknik penentuan sampel bila semua anggota populasi digunakan menjadi sampel.Jumlah sampel penelitian ini adalah sebanyak 20 orang yang tergabung dalam ekstrakulikuler renang SMP Islam Al-Hasanah Rekat Lauk. Adapun variabel yang digunakan dalam penelitian ini adalah dua variabel. Variabel pembelajaran audio visual (variable bebas) dan kemampuan renang gaya dada (variable terikat). Dalam Pengumpulan data-data penelitian menggunakan tes.Metode tes digunakan untuk memperoleh data-data tentang variable terikat yaitu data mengenai kemampuan renang gaya dada dengan menggunakan tes praktik teknik dasar renang gaya dada. Instrumen yang digunakan untuk memperoleh datadata tentang kemampuan renang gaya dada sebagai variable terikat dalam penelitian ini adalah Lembar observasi. Sesuai dengan rancangan yang digunakan dalam penelitian ini 
yang dikaitkan dengan rumusan masalah dan tujuan penelitian, maka analisis data yang digunakan adalah analisis statistic dengan menggunakan rumus $\mathrm{T}$ test.

\section{Hasil dan Pembahasan}

Hasil

Berdasarkan hasil penelitian diperoleh hasil tes kemampuan teknik renang gaya dada secara benar ialah sebagaimana terlihat pada table dibawah ini :

Tabel 1. Data kemampuanpre-test \&pos-test renang gaya dada

\begin{tabular}{ccccc} 
JumlahSampel & \multicolumn{2}{c}{ Prestasi } & Gain $(\mathrm{d})=$ & $\mathrm{X}^{2}{ }_{\mathrm{d}}$ \\
\hline & $\begin{array}{c}\text { Pre-test } \\
\left(\mathrm{X}_{1}\right)\end{array}$ & $\begin{array}{c}\text { Pos-test } \\
\left(\mathrm{X}_{2}\right)\end{array}$ & $\mathrm{X}_{2}-\mathrm{X}_{1}$ & \\
\hline 20 & 51,2 & 75,3 & 24,1 & 2,9895
\end{tabular}

Memasukkan data kedalam rumus :

$$
\begin{aligned}
& \mathrm{Md}=\frac{\Sigma d}{\mathrm{~N}}=\frac{24,1}{20}=1.205 \\
& \mathrm{t}=\frac{\mathrm{Md}}{\sqrt{\frac{\Sigma x^{2} d}{N(N-1)}}} \\
& \mathrm{t}=\frac{1.205}{\sqrt{\frac{2,9895}{20(20-1)}}} \\
& \mathrm{t}=\frac{1.205}{\sqrt{\frac{2,9895}{380)}}} \\
& \mathrm{t}=\frac{1.205}{\sqrt{0,00786710526}} \\
& t=\frac{1,205}{0,08869} \\
& \mathrm{t}=13,586
\end{aligned}
$$

Dari hasil penelitian yang dilakukan pada siswa SMP Islam Al-Hasanah Rekat Lauk sebelum diberikan sebuah perlakuan (nonton video) kemampuan renang gaya dada yang diperoleh sebesar $(51,2)$ dan setelah diberikan perlakuan selama 2 bulan maka kemampuan yang dimiliki oleh para siswa sebesar $(75,3)$. Berdasarkan hasil tersebut terjadi peningkatan yang signifikan sebesar $(24,1)$. Dari hasil penelitian menunjukkan bahwa siswa yang 
diberikan nonton video setiap 3 kali seminggu ternyata kemampuan renang gaya dada meningkat dibandingkan dengan sebelum diberikan nonton video. Setelah mendapatkan nilai $t_{\text {hitung }}$ sebesar 13,586 kemudian nilai $t_{\text {tabel }}$ dengan derajat kebebasan (df) N-1 (20-1) = 19. Untuk dapat menolak hipotesi nihil $H_{0}$ diperlukan nilai $t_{\text {hitung }}$ sama atau lebih besar dari nilai $t_{\text {tabel }}$ dan pada taraf signifikan 5\% menunjukan angka sebesar 1,729 atau dengan kata lain nilai $t_{\text {hitung }}$ yang diperoleh lebih besar dari $t_{\text {tabel }}(13,586>1,729)$.

\section{Pembahasan}

Berdasarkan Hasil penelitian menunjukkan bahwa ada pengaruh pembelajaran audio visual (video) terhadap kemampuan renang gaya dada pada siswa SMP Islam Alhasanah Rekat Lauk. Hal ini dibuktikan dengan perbedaan hasil antara Pree test dan Post tes. Dari hasil gerakan gaya dada maka hasil dari gerakkan kombinasinya adalah sebesar 51,2 dan setelah diberikan perlakuan selama 2 bulan maka kemampuan yang dimiliki oleh para siswa sebesar 75,3. Berdasarkan hasil tersebut terjadi peningkatan yang signifikan sebesar 24,1. Dari hasil penelitian menunjukkan bahwa siswa yang diberikan nonton video setiap 3 kali seminggu ternyata kemampuan renang gaya dadanya meningkat dibandingkan dengan sebelum diberikannya nonton video. Hasil penelitian ini diperkuat oleh Didik Setyawarno (2014: 12) Dalam proses pembelajaran, media memiliki fungsi sebagai pembawa informasi atau pesan dari sumber (guru) menuju penerima (siswa). Sedangkan metode adalah prosedur untuk membantu siswa dalam menerima dan mengolah informasi atau pesan guna mencapai tujuan pembelajaran. Dan hasil penelitian Rizal Bastomi (2018:8) dalam penelitiannya bahwa media audio visual tersebut berpengaruh signifikan pada siswa kelas VIII SMP 3 Sidoardjo. Dengan demikian dapat disimpulkan bahwa dengan sering menonton video maka bisa meningkatkan kemampuan renang gaya dada. Sebelum adanya perlakuan nonton video 3 kali seminggu selama 2 bulan, banyak siswa yang memiliki kemampuan renang gaya dada yang rendah, dan setelah diberikannya perlakuan nonton video 3 kali seminggu selama 2 bulan dan hasilnya menunjukan adanya penigkatan pada kemampuan renang gaya dada pada siswa Smp Islam Alhasanah Rekat Lauk.

\section{Simpulan}

Berdasarkan hasil penelitian dan pembahsan yang telah di uraikan di atas, maka dapat disimpulkan bahwa program perlakuan memberikan siswa nonton video selama 3 kali seminggu dalam jangka 2 bulan dapat meningkatkan kemampuan siswa dalam melakukan renang gaya dada. Hal ini di buktikan dengan nilai sebelum perlakuan sebesar 51,2 (pretest) dan setelah diberikan perlakuan hasilnya menunjukkan sebesar 75,3 (posttest). Sedangkan rerata peningkatan sebesar 24,1 (selisih peningkatan). Hal ini menunjukkan adanya peningkatan yang signifikan pada kemampuan renang gaya dada dimana $t_{\text {hitung }} 13,586>$ $t_{\text {tabel }} 1,729$ dengan taraf signifikan 5\%. Sehingga dapat disimpulkan bahwa ada pengaruh pembelajaran audio visual (video) terhadap kemampuan renang gaya dada pada siswa SMP Islam Al-Hasanah Rekat Lauk. Pada penelitian berikutnya diharapkan untuk meningkatkan kemampuan renang gaya dada siswa tidak hanya belajar dan diberikan materi secara langsung dari guru saja, tetapi dapat juga dilakukan dengan memberikan siswa menonton video agar mereka tidak jenuh dan bias melihat langsung teknik renang gaya dada, hasil penelian ini dapat dijadikan refrensi bagi peneliti yang melakukan penelitian yang sama dan selain dengan metode menonton video, belajar teknik dan fisik tentu harus diperhatikan dan dikedepankan.

\section{Daftar Pustaka}

Arsyad, Azhar. 2011. Media Pembelajaran. Jakarta: PT Raja grafindo Persada. Budiningsih, Annayanti.2017. Renang Gaya Bebas. Kudus: PT Pura Barutama. 
Budiwanto, setyo. 2012. Metodologi Latihan Olahraga. Malang: Universitas Negeri Malang (UM Press).

Daniyantara, D. (2018). Pembangunan Olahraga Kota Selong Kabupaten Lombok Timur Ditinjau Dari Sport Development Index. Jurnal Porkes, 1 (2), 32-36.

Muliarta, I dan Giri, Made. 2015. Jurnal Internasional Vol.17. Jakarta Pusat: Kementrian Pemudadan Olahraga R.I.

Ngatiyono. 2012. Pendidikan Jasmani, Olahraga, dan Kesehatan. Solo: PT Tiga Serangkai Pustaka Mandiri.

Nurhidayat, N., \& Sistiasih, V. S. (2019). Peningkatan Hasil Belajar Forehand Drive dan Backhand Drive Tenis Meja Melalui Penerapan Media Pembelajaran Audio Visual. Jurnal Porkes, 2 (2), 58-63.

Prasetyo, Edo dan Moch. Yunus. 2017.Hubungan antara Frekuensi Gerakan Kaki dengan Prestasi Renang Gaya Crawl 50 Meter. Malang: Universitas Negeri Malang. Indonesia Performance Journal 1 (2) (2017).

Putri Ramadhan, Mutiara.2017. Pengaruh Media Audio Visual Terhadap Keterampilan Berbicara Siswa Kelas Iv Min 7 Bandar Lampung Tahun Ajaran 2017/2018. Lampung: Universitas Islam Negeri.

Riduwan \& Sunarto.2009.Pengantar Statistika. Bandung: ALFABETA.

Rizal Bastomi, Muhamaad dan Setiyo Hartoto.2018. Pengaruh Penerapan Media Audio Visual Terhadap Hasil Belajar Renang Gaya Dada.Universitas Negeri Surabaya. Jurnal Pendidikan Olahraga dan Kesehatan Volume 06 Nomor 01 Tahun 2018, 5 9.

Sistiasih, V. S. (2020). Peningkatan Penguasaan Teknik Renang Gaya Dada Dengan Metode Pembelajaran Resiprokal. Jurnal Porkes, 3(1), 63-70.

Sanaky, Hujair AH.2013.Media Pembelajaran Intraktif-Inovatif. Yogyakarta: Kaukaba Dipantara.

Subagyo. 2008. Teknik Renang. Bogor: Dahlia.

Sugiyanto, FX. 2010. Peningkatan Pembelajaran Dasar Gerak Renang Melalui Pendekatan Penggunaan Alat Bagi Mahasiswa PKO PemulaTahunAjaran 2010.Jurnal Evaluasi dan Penelitian Pendidikan. Yogyakarta: FIK UNY.

Suharsimi Arikunto, Prosedur Penelitian Suatu Pendekatan Praktik, (Jakarta: Rineka Cipta, 2010), hal. 4 Suyono \& Hariyanto. 2011. Belajar dan Pembelajaran. Bandung: PT Remaja Rosda karya. 